Research Article

\title{
Reliability-Based Opportunistic Maintenance Modeling for Multi-Component Systems with Economic Dependence under Base Warranty
}

\author{
Rongcai Wang $\left(\mathbb{D}\right.$, Zhonghua Cheng $\mathbb{D}^{D}$, Enzhi Dong, Chiming Guo, and Liqing Rong \\ Shijiazhuang Campus of Army Engineering University, Shijiazhuang 050003, China \\ Correspondence should be addressed to Zhonghua Cheng; 13143648622@163.com
}

Received 7 April 2021; Revised 15 April 2021; Accepted 26 April 2021; Published 7 May 2021

Academic Editor: Chun Wei

Copyright ( 92021 Rongcai Wang et al. This is an open access article distributed under the Creative Commons Attribution License, which permits unrestricted use, distribution, and reproduction in any medium, provided the original work is properly cited.

\begin{abstract}
Maintenance usually plays a key role in controlling a multi-component production system within normal operations. Furthermore, the failure of components in the production system will also cause large economic losses for users due to the shutdown. Meanwhile, manufacturers of the production system will be confronted with the challenges of the warranty cost. Therefore, it is of great significance to optimize the maintenance strategy to reduce the downtime and warranty cost of the system. Opportunistic maintenance $(\mathrm{OM})$ is a quite important solution to reduce the maintenance cost and improve the system performance. This paper studies the OM problem for multi-component systems with economic dependence under base warranty (BW). The irregular imperfect preventive maintenance (PM) is performed to reduce the failure rate of components at a certain PM reliability threshold. Moreover, the OM optimization model is developed to minimize the maintenance cost under the optimal OM reliability threshold of each component. A simulated annealing (SA) algorithm is proposed to determine the optimal maintenance cost of the system and the optimal OM threshold under BW. Finally, a numerical example of a belt conveyor drive device in a port is introduced to demonstrate the feasibility and advantages of the proposed model in maintenance cost optimization.
\end{abstract}

\section{Introduction}

1.1. Motivation. With the rapid development of modern production technology, manufacturers gradually switch their attention from product-oriented to service-oriented to highlight the brand value and capture more market share [1]. In such a situation, an increasing number of products are sold with attractive warranty policies [2]. Warranty is prevalent in many markets, in which warranty plays an increasingly key role between customers and manufacturers [3]. Warranty is incurred by manufacturers in connection with the sale of products [4], whose initial purpose is to protect users from defective items [5]. Nowadays, warranty policies have played a significant role in marketing in essence, including indicating product quality and increasing customer's satisfaction [6]. On the one hand, as a protection role, warranty is an obligation specified in the maintenance contract that manufacturers must repair or replace the failed products free of charge to customers during the warranty period [7]. Generally speaking, warranty cost may account for 2 to $10 \%$ of the sale price relying on the products and manufacturers [8]. On the other hand, as a promotion role, a more attractive warranty policy can obtain higher customer satisfaction and capture more market share $[9,10]$. Therefore, manufacturers are faced with a balance between warranty cost and boosting product demand when formulating the warranty policies. Therefore, optimizing the maintenance strategy to reduce the maintenance cost during the warranty period is well worthy of research. Warranty can be divided into two categories according to the time sequence: base warranty (BW) and extended warranty (EW) [11]. BW is usually provided by the manufacturers as an essential part of the sale price of products [12]. At the end of BW, manufacturers usually provide customers with an option to purchase EW [13]. In practice, customers can choose whether to purchase EW or not at the end of BW [14]. 
In terms of modern production systems such as wind turbines and assembly line equipment, they usually consist of several interdependent components or subsystems. The maintenance actions of these systems play a key role in their sufficient usage in terms of cost, reliability, and availability [15]. The key of maintenance actions is to determine the right opportune moments, which is usually achieved by maintenance modeling. However, the modeling of failure process and maintenance optimization within production requirements is difficult due to the complexity of the product system; that is, many components in the system are interdependent with each other. Many pieces of the early literature published on maintenance optimization modeling dealt with single-component systems [16-18]. In recent years, with the development of production technology, most manufacturing systems become increasingly complicated in terms of structure and function and comprise multiple components with various dependencies. Moreover, the dependencies between the components should be taken into account essentially in maintenance modeling decisions. Therefore, new methods as well as targeted strategies and models are needed to solve these maintenance problems of complex systems. Multi-component systems have been increasingly adopted in nowadays [19]; that is, a power system of the wind turbine consists of a generator, converter, and transformer. Maintenance optimization of a multi-component system relies on the dependence between components, which includes economic dependence, stochastic dependence, and structural dependence [20]. Economic dependence means that group maintenance [21] of components is either cheaper (positive economic dependence) or more expensive (negative economic dependence) than individual repair of these components [15]. There are some studies focusing on considering the economic dependence between components $[22,23]$. Stochastic dependence implies that the deterioration or failure processes of components are interdependent to a certain extent [24], while structural dependence concerns the structural relationships between different components in a system and focuses on the situation where the maintenance or replacement of a component requires the disassembly or replacement of other components in the system [25]. Maintenance including preventive and corrective actions is implemented to keep the system in or restore it to a specified technical condition [26]. Generally speaking, for retaining a system in its normal operating condition, implementing proper preventive maintenance $(\mathrm{PM})$ during its servicing life is an essential way. Barlow [27] first proposed the minimal repair model, after which various PM models [28] have been widely studied and developed to reduce the unscheduled shutdown, improve the system reliability and availability, and minimize maintenance costs [29].

For the maintenance actions of multi-component systems, most of which are carried out in the after-sales warranty period of the systems. Therefore, optimizing maintenance strategies to reduce warranty costs is of great significance to manufacturers and consumers, which can improve the profits of manufacturers and product reliability, thereby reducing shutdown loss for consumers. In the maintenance optimization framework of multi-component systems, opportunistic maintenance (OM) has been introduced, developed and successfully applied to various multi-component systems. The main idea of OM is to take the advantage of positive economic dependence, which means that group maintenance actions are cheaper than implementing maintenance actions on components separately $[30,31]$. As a maintenance strategy for multi-component systems, OM refers to the PM or preventive replacement of other components that reach the maintenance threshold in advance when a component in the system is in maintenance action, so as to reduce the number of maintenance actions, unavailable time, and maintenance cost of the system and solve the maintenance optimization problems such as overrepair, out of repair and failure risk. In terms of multi-component systems, an inspection or maintenance action of one component provides an early PM opportunity to the others [32]. OM is to consider the degradation status of all components in the system and formulate the maintenance threshold for components. First, the PM threshold of a component will be judged. If it meets the reliability threshold, the PM action will be carried out. At this time, the OM threshold of the remaining components needs to be judged. If the degradation status reaches the preset OM threshold, it will be repaired. Because OM takes into account the degradation of different components, the OM strategy is more accurate. The advantages of OM include that the setup cost and downtime can be shared by group maintenance actions, which is significant for multi-component systems. $\mathrm{OM}$ aims to identify the best maintenance thresholds and combination of the components, improving the system economy. The OM strategy has drawn a lot of attention from scholars, and the OM model has a wide range of applications in engineering systems. Many pieces of literature have studied $\mathrm{OM}$ in depth and many kinds of $\mathrm{OM}$ models have been introduced [33, 34]. Related theoretical methodologies and practical applications in $\mathrm{OM}$ were reviewed and summarized by Ab-Samat [35]. Ding [36] studied the OM strategy for wind farms and reduced maintenance costs by adopting an imperfect OM strategy. Cavalcante [37] discussed the OM policy, considering more than one decision criterion by using a multiattribute value function, and defined $\mathrm{OM}$ in a cogeneration system as a basis for decision-making with minimal repair, OM, and PM. Moreover, Vu [38] developed a dynamic OM approach for multi-component redundant systems. To find the best $\mathrm{OM}$ scenario, an efficient genetic algorithm optimization with memory is developed.

1.2. Contributions of This Work. However, in the above studies, there is no literature to carry out BW decisionmaking researches based on OM strategy for multi-component systems with economic dependence. In traditional maintenance models, most of the modeling studies on BW assume that the components are independent of each other in the system. Model construction and solution are less difficult, but there is a big error between the maintenance 
process and the actual situation. Therefore, in BW studies, simply treating the components in the system as independent of each other is not in line with the actual situation. It is necessary to consider the economic dependence between the components in the system to make the maintenance process more consistent with the actual situation. This paper intends to fill this gap.

In the current study, an OM strategy is introduced to minimize the maintenance cost for multi-component systems with economic dependence during the BW period. Due to the advanced materials, technology, and complex structure of the multi-component system, maintenance actions usually cannot achieve the perfect update of the system [39], but the failure rate of the system after maintenance action is reduced, which is between "as good as new" and "as bad as old," that is, imperfect repair [40,41]. However, the overall trend of system failure rate is rising. Therefore, an irregular imperfect PM according to the reliability threshold of each component is proposed and investigated. Thereby, in the OM strategy of this paper, the maintenance methods for components mainly include imperfect PM, minimal repair, and OM. Moreover, in order to get closer to engineering practice and ensure the system reliability, preventive replacement will be derived and applied to the components after a certain number of imperfect PM actions are implemented on them. Considering the degradation process, this paper judges the OM condition of other components at the moment of PM or preventive replacement of a component in the system and determines whether other components need PM or preventive replacement by comparing with their OM reliability thresholds. On this basis, we can implement PM on the components whose PM moments are close together, which can effectively reduce the number of shutdowns and downtime of the system and simultaneously reduce the maintenance cost of the system during $\mathrm{BW}$ period, which is a win-win strategy for users and manufacturers.

Therefore, the remainder of this paper is organized as follows: Section 2 describes the model assumptions and notations. Next, to construct the OM model of the multi-component system under BW, the description of the failure model and OM model is presented under the logical framework in Section 2. Then, we first develop an optimization of PM interval for a single component based on reliability. On this basis, the OM model of the multi-component system under BW is proposed in Section 3. A numerical example is then given in Section 4 to illustrate the optimization effect of OM strategy on reducing the maintenance cost of a multi-component system with economic dependence under BW using the simulated annealing (SA) algorithm. Finally, the conclusions and potential future research directions are summarized in Section 5.

\section{Model Description and Assumptions}

The paper studies a series multi-component system composed of $\mathrm{Q}$ components with different failure rates, and the OM strategy is implemented during the BW period $[0, W]$. When a component undergoes maintenance actions, it will cause the system to shut down for a certain period of time.
Every time the system shuts down for the maintenance actions, regardless of the number of maintenance tasks, high fixed maintenance costs, such as the disassembly and assembly of maintenance equipment and commissioning cost, will be incurred. Therefore, for multi-component systems with economic dependence, the shutdown loss can be reduced by reducing the number of system shutdowns. At the same time, to ensure the reliability requirements of the components within the normal operation in the system, PM is required. With the time going and the implementation of imperfect PM, the failure rate of each component will increase to a certain extent. It is difficult to maintain the reliability of the components with the periodic PM strategy, and the number of system failures will also increase. The correct maintenance method should be to appropriately shorten the PM interval of the components and increase the number of PMs as the service age of the system increases, so as to ensure system reliability. Moreover, in this paper, when the reliability of component $i$ reaches its lowest reliability $R_{i \text { min }}$ during operation, the PM will be implemented immediately. However, the PM interval of each component is different. If the system shuts down for the PM actions in strict accordance with the maintenance interval of each component, it will inevitably cause frequent system shutdowns. In terms of the components that meet the OM conditions in the series multi-component system, their PM work will be carried out in advance together with the components involved in a PM action, which can effectively reduce the number of system shutdowns and maintenance cost.

2.1. Model Assumptions. To facilitate the research, the system modeling is based on the following assumptions:

(1) Each component of the series multi-component system is repairable, and the failure distribution between the components is independent of each other obeying the two-parameter Weibull distribution.

(2) If a component fails during the PM interval, the minimal repair will be implemented on it immediately and the minimal repair will not bring maintenance opportunities to other components.

(3) OM includes opportunistic PM and opportunistic replacement.

(4) In the series multi-component system, the failure of any component will result in the shutdown of the whole system.

(5) Before the reliability of component $i$ reaches its PM reliability threshold $R_{i \min }$, the PM or replacement is allowed to be implemented on component $i$ in advance, and the maintenance actions of each component in the system are allowed to be carried out in parallel.

2.2. Model Notations. The following and notations are used in this paper. 
$W$ : deadline of BW

$R_{i \text { min }}$ : PM reliability threshold of component $i$

$T_{i k}$ : the kth PM interval of component $i$

$T_{i k}^{*}$ : the optimal PM interval of component $i$

$T_{p i}$ : time consuming of a single PM for component $i$

$T_{f i}$ : time consuming of a single minimal repair for component $i$

$T_{r i}$ : time consuming of a single replacement for component $i$

$C_{p i}$ : cost of a single PM for component $i$

$C_{f i}$ : cost of a single minimal repair for component $i$

$C_{r i}$ : cost of a single replacement for component $i$

$\lambda_{i}(t)$ : the failure rate function of component $i$

$R_{i}$ : OM reliability threshold of component $i$

$R_{i}(t)$ : the reliability function of component $i$

$N_{i}$ : the number of PMs for component $i$ in a life cycle

$n_{i}$ : the number of PMs of component $i$

$N$ : the number of system shutdowns for maintenance during the $\mathrm{BW}$ period $[0, W]$

$N_{i}^{*}$ : the optimal number of PMs for component $i$ in a life cycle

$C_{D}$ : shutdown loss per unit time of the belt conveyor drive device

$t_{i n}$ : the nth PM moment of component $i$

$t_{n}$ : the nth PM moment of the multi-component system

$M_{i t_{n}}$ : the maintenance methods of component $i$ at $t_{n}$; among them, Y: PM; G: preventive replacement; O: opportunistic PM; R: opportunistic preventive replacement; B: no maintenance actions

$S_{p d n}:$ the nth PM downtime of the system

$T_{\text {pit }_{n}}$ : time consuming of PM for component $i$ at $t_{n}$

$T_{\text {rit }_{n}}$ : time consuming of replacement for component $i$ at $t_{n}$

2.3. Failure Model Description. In practice, most components in the multi-component system are composed of the parts with different failure forms, and the failure rate function generally presents an increasing trend in the operation cycle. The bathtub curve can better describe the failure law, as shown in Figure 1.

The bathtub curve describes the three stages of decreasing, stabilizing, and increasing the failure rate of the component during the service life. Weibull distribution is used to describe the failure distribution of the component, which is suitable for each stage of the bathtub curve. It is assumed that the component life in the multi-component system obeys the two-parameter Weibull distribution. The failure rate function of component $i$ can be described as

$$
\lambda_{i}(t)=\frac{\alpha_{i}}{\beta_{i}}\left(\frac{t}{\beta_{i}}\right)^{\alpha_{i}-1} .
$$

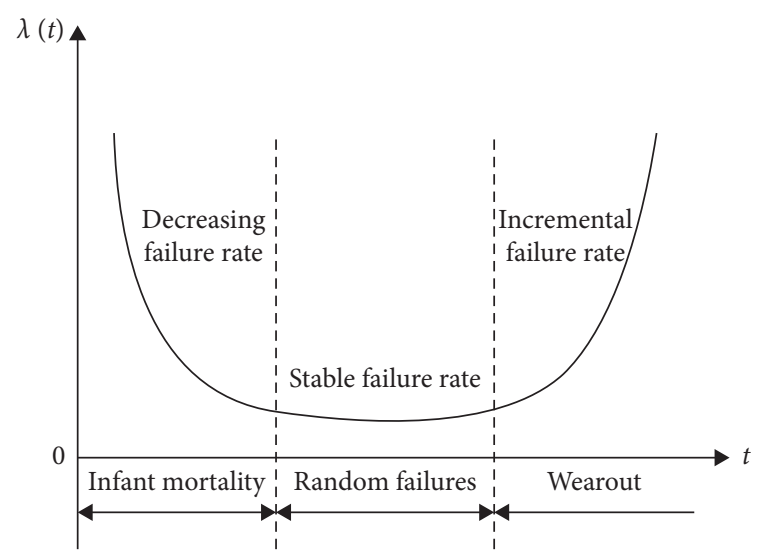

Figure 1: Bathtub curve of failure rate.

Among them, $\alpha_{i}$ and $\beta_{i}$ are the shape parameter and scale parameter of component $i$, respectively.

In terms of the failure model for imperfect repair, Malik [42] first proposed the age reduction factor to model imperfect repair. Assuming that $\lambda_{i k}(t)$ represents the failure rate of component $i$ during the kth PM interval, the failure rate after the kth $\mathrm{PM}$ recovers as follows:

$$
\lambda_{i(k+1)}(t)=\lambda_{i k}\left(t+\delta_{i k} T_{i k}\right), \quad t \in\left(0, T_{i(k+1)}\right),
$$

where $\delta_{i k}\left(0<\delta_{i k}<1\right)$ is the age reduction factor, indicating that when the PM process is not perfect, the system failure rate will be reduced after each repair, but it will never return to the original functional state [43].

Nakagawa [44] first introduced a different failure model for imperfect repair, in which the failure rate of component $i$ after the kth maintenance action is as follows:

$$
\lambda_{i(k+1)}(t)=\varphi_{i k} \lambda_{i k}(t), \quad t \in\left(0, T_{i(k+1)}\right) .
$$

Among them, $\varphi_{i k}\left(\varphi_{i k}>0\right)$ denotes the failure rate increase factor. In this model, the system will recover the state of "as good as new" after each repair but will fail faster than before. Moreover, Lin et al. [45] presented a hybrid failure rate model that combines the age reduction factor and failure rate increase factor. It can be derived as

$$
\lambda_{i(k+1)}(t)=\varphi_{i k} \lambda_{i k}\left(t+\delta_{i k} T_{i k}\right), \quad t \in\left(0, T_{i(k+1)}\right) .
$$

Equation (4) shows that when $\varphi_{i k}$ is closer to 1 and meanwhile $\delta_{i k}$ is closer to 0 , the maintenance effect is better. Therefore, the hybrid model component $i$ shown in Figure 2 can comprehensively illustrate the variation rule of failure rate and reliability during each maintenance cycle.

2.4. OM Model Description. The key to the OM strategy is to determine the OM reliability threshold $R_{i}$ of component $i$. On one hand, the larger the $R_{i}$ is, the earlier the PM or replacement moments of component $i$ will be. However, during the $\mathrm{BW}$ period $[0, W]$, the number of PMs or replacement for component $i$ will also increase, which will increase the maintenance cost and easily cause overrepair of the component. On the other hand, the smaller the $R_{i}$ is, the 


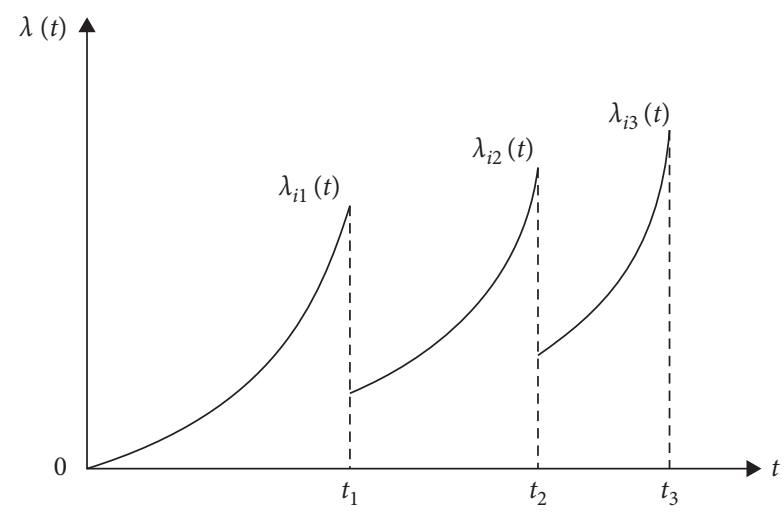

FIgURE 2: Failure rate change of imperfect repair.

easier the failure will occur, which will lead to the disrepair of the component. That not only affects the normal operation of the system but also increases the maintenance cost and downtime. The relationship curve between the maintenance cost of the series multi-component system and the change of $R_{i}$ is shown in Figure 3 .

The OM strategy needs to adjust the PM interval of the single component, but the extension of the PM interval will make the reliability of the component lower than its PM reliability threshold, increasing the probability of component failure; however, shortening the PM interval of the component will cause the overrepair and increase the maintenance cost and downtime. Therefore, only the OM for the component that meets a certain control condition can effectively reduce the maintenance cost of the system, thereby reducing the BW cost of the system. Since the imperfect PM is implemented, the components cannot be restored as good as new after the PM, and the failure rate will increase to a certain extent. Hence, after $\mathrm{N}$ times of PM for the component, the failure rate will increase to an unbearable range. At this time, preventive replacement of the component is a more economical maintenance method. Suppose that component $i$ is replaced at the moment of the $\left(N_{i}+1\right)$ thPM. After the replacement, the component returns to be new and a complete life cycle ends. Furthermore, the standard for PM of component $i$ is that the reliability of component $i$ during operation reaches its PM reliability threshold $R_{i \min }$. Then the PM process of component $i$ in the series multi-component system under the OM strategy is shown in Figure 4.

At the moment $t_{i n}$ of the nth PM for component $i$ in the multi-component system, it should be judged whether component $u$ satisfies the OM condition. The difference between the reliability $R_{u}\left(t_{i n}\right)$ of component $u$ at $t_{\text {in }}$ and its PM reliability threshold $R_{u \text { min }}$ and the OM reliability threshold $R_{u}$ are compared, as presented in Figure 5.

(1) If $R_{u}\left(t_{i n}\right)-R_{u \min } \leq R_{u}$, the PM for component $u$ will be carried out. If the number of PMs for component $u$ reaches $N_{u}+1$ and $R_{u} \leq R_{u \text { min }}$ at the moment, the opportunistic replacement for component $u$ will be implemented.

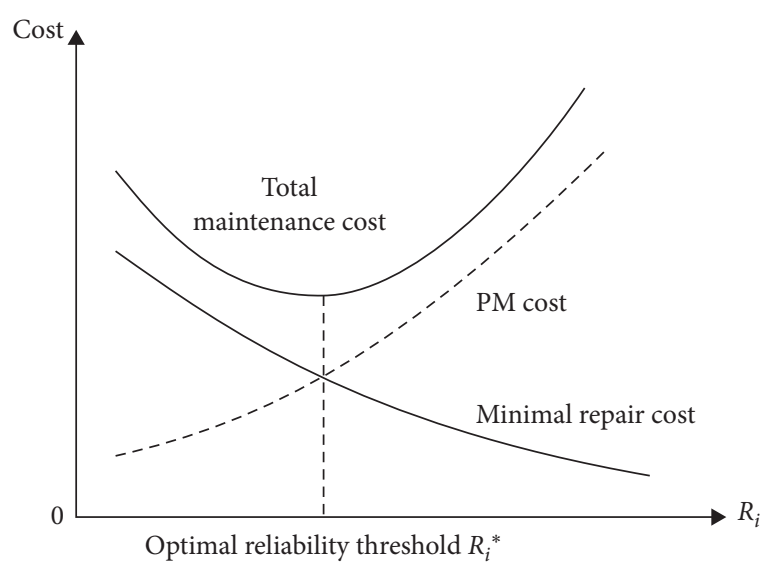

FIgURE 3: The curve of system maintenance cost.

(2) If $R_{u}\left(t_{i n}\right)-R_{u \min }>R_{u}$, then no maintenance actions will be implemented on component $u$.

After completing an OM, component $u$ enters the next PM interval. When a certain component in the system needs $\mathrm{PM}$, then analyze whether other components in the system need an OM. From the description of the OM model, it is crucial to solving the optimal solution $R^{*}=\left(R_{1}^{*}, \ldots, R_{i}^{*}, \ldots, R_{Q}^{*}\right)$ of the OM reliability threshold for each component in the multi-component system.

\section{Methodology}

3.1. Optimization of PM Strategy for a Single Component Based on Reliability. Before implementing the OM strategy for the multi-component system, the optimal PM strategy for each single-component needs to be formulated. On the basis of the maintenance plan for each single component, the $\mathrm{OM}$ for other components is considered when PM actions are carried out for a component in the system. The normal operation of the series multi-component system is usually closely related to the reliability of each single component. When the reliability of a component is lower than the reliability threshold, there will be great hidden trouble in the operation of the system. At this time, it is necessary to implement PM or replacement on the component. During the BW period $[0, W]$, when the reliability of the component is lower than the PM reliability threshold, the PM will be performed. According to the reliability theory, the reliability function of component $i$ is as follows:

$$
R_{i}(x)=\exp \left[-\int_{0}^{x} \lambda_{i}(t) \mathrm{d} t\right] .
$$

Then, the cumulative failure distribution function of component $i$ in the kth PM interval can be written as follows:

$$
H_{i}\left(T_{i k}\right)=\int_{0}^{T_{i k}} \lambda_{i k}(t) \mathrm{d} t .
$$

Therefore, the reliability equation of component $i$ can be expressed as 


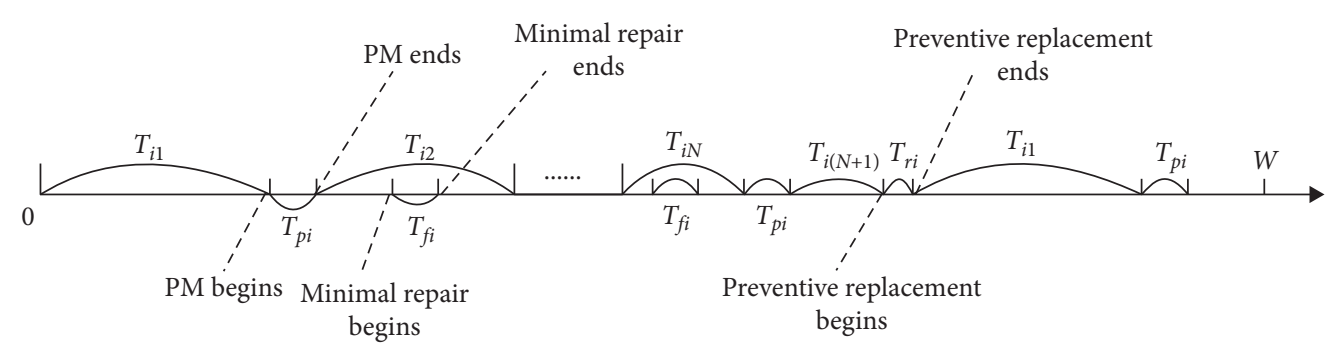

FIgURE 4: Preventive maintenance (PM) process for component $i$.

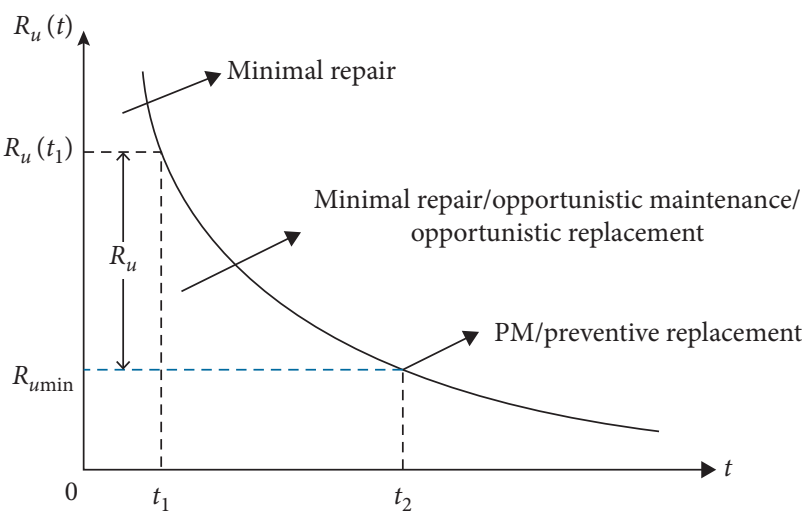

Figure 5: The OM reliability threshold of component u.
Taking the logarithm of both sides at the same time, it can be derived as

$$
\int_{0}^{T_{i 1}} \lambda_{i 1}(t) \mathrm{d} t=\int_{0}^{T_{i 2}} \lambda_{i 2}(t) \mathrm{d} t=\cdots=\int_{0}^{T_{i k}} \lambda_{i k}(t) \mathrm{d} t=-\ln R_{i \min }
$$

It can be seen from equation (8) that when reliability is the constraint, the number of minimal repairs for component $i$ in each PM interval is equal under the constraint of reliability, which are both $-\ln R_{i \text { min }}$. During the BW period, the maintenance cost per unit time of component $i$ during the entire life cycle is

$$
\begin{aligned}
\exp \left[-\int_{0}^{T_{i 1}} \lambda_{i 1}(t) \mathrm{d} t\right] & =\exp \left[-\int_{0}^{T_{i 2}} \lambda_{i 2}(t) \mathrm{d} t\right] \\
& =\cdots=\exp \left[-\int_{0}^{T_{i k}} \lambda_{i k}(t) \mathrm{d} t\right]=R_{i \min }
\end{aligned}
$$

$$
E C_{i}=\frac{N_{i}\left[C_{f i}\left(-\ln R_{i \min }\right)+C_{p i}+C_{D}\left(T_{p i}+T_{f i}\left(-\ln R_{i \min }\right)\right)\right]+C_{f i}\left(-\ln R_{i \min }\right)+C_{D}\left(T_{r i}+T_{f i}\left(-\ln R_{i \min }\right)\right)+C_{r i}}{\sum_{k=1}^{N_{i}}\left[T_{i k}+T_{p i}+T_{f i}\left(-\ln R_{i \min }\right)\right]+T_{i\left(N_{i}+1\right)}+T_{r i}} .
$$

By minimizing the objective function, the optimal number $N_{i}^{*}$ of PM for component $i$ and the optimal PM interval $T_{i k}^{*}$ can be obtained. The optimization equation is as follows:

$$
\left\{\begin{array}{l}
\min E C_{i}=\frac{N_{i}\left[C_{f i}\left(-\ln R_{i \min }\right)+C_{p i}+C_{D}\left(T_{p i}+T_{f i}\left(-\ln R_{i \min }\right)\right)\right]+C_{f i}\left(-\ln R_{i \min }\right)+C_{D}\left(T_{r i}+T_{f i}\left(-\ln R_{i \min }\right)\right)+C_{r i}}{\sum_{k=1}^{N_{i}}\left[T_{i k}+T_{p i}+T_{f i}\left(-\ln R_{i \min }\right)\right]+T_{i\left(N_{i}+1\right)}+T_{f i}\left(-\ln R_{i \min }\right)+T_{r i}} \\
\text { s.t. } \quad \int_{0}^{T_{i k}} \lambda_{i k}(t) \mathrm{d} t=-\ln R_{i \min } \\
R_{i \min }>0 ; N_{i}>0 ; i=1,2,3, \ldots, N_{i} ; T_{i k} \geq 0 .
\end{array}\right.
$$


3.2. OM Model of the Multi-component System under BW. During the BW period $[0, W]$, the maintenance cost of the multi-component system mainly includes the direct maintenance cost $C_{z}$, PM shutdown loss $C_{p d}$, and minimal repair shutdown loss $C_{f d}$. For component $i$ in the system, the direct maintenance cost is divided into PM cost $C_{p i}$, preventive replacement cost $C_{r i}$, and minimal repair cost $C_{F i}$. In the series multi-component system, the failure of a component will cause the entire system to shut down, so the shutdown loss per unit time $C_{D}$ caused by the maintenance actions of each component in the system is equal.

3.2.1. Direct Maintenance Cost $C_{z}$. During the whole PM cycle from the nth PM at $t_{\text {in }}$ to the $(n+1)$ th PM at $t_{i(n+1)}$, the direct maintenance cost of component $i$ is

$$
C_{z i n}= \begin{cases}C_{F i}, & M_{i t_{n}}=B, \\ C_{p i}+C_{F i}, & M_{i t_{n}}=Y, O, \\ C_{r i}+C_{F i}, & M_{i t_{n}}=G, R,\end{cases}
$$

where $C_{F i}$ represents the minimal repair cost of component $i$ in a PM cycle; then

$$
C_{F i}=C_{f i}\left(-\ln R_{i \min }\right),
$$

where $C_{i}$ denotes the direct repair cost of component $i$ during the $\mathrm{BW}$ period $[0, W]$. It can be obtained as

$$
C_{i}=\sum_{n=1}^{N} C_{z i n}
$$

Therefore, the direct maintenance cost of the multi-component system during the $\mathrm{BW}$ period $[0, W]$ is as follows:

$$
C_{z}=\sum_{i=1}^{Q} \sum_{n=1}^{N} C_{z i n}
$$

3.2.2. PM Shutdown Loss $C_{p d}$. The system shutdown loss is usually proportional to downtime. The system downtime $S_{D}$ includes PM downtime $S_{p d}$ and minimal repair downtime $S_{f d}$. When the nth PM is performed on the system, the longest maintenance time is selected as the system downtime among all components that need to be repaired. It can be defined as

$$
S_{p d n}=\max _{1 \leq i \leq Q}\left(T_{p i t_{n}}, T_{r i t_{n}}\right)
$$

Thus, the PM shutdown loss of the system during the $\mathrm{BW}$ period $[0, W]$ can be derived as follows:

$$
C_{p d}=C_{D} S_{p d}=C_{D} \sum_{n=1}^{N} S_{p d n}
$$

3.2.3. Minimal Repair Shutdown Loss $C_{f d} \cdot m_{i}$ is the number of PMs for component $i$ during the $\mathrm{BW}$ period $[0, W]$. Assuming that $m_{i}=\delta_{i} N_{i}+\kappa_{i},\left(\delta_{i}, \kappa_{i}=0,1,2, \ldots\right)$, where $\delta_{i}$ is the number of replacements of component $i$ during the BW period and $\kappa_{i}$ represents the number of PM actions that have elapsed since the last replacement of component $i$ during the BW period. $T_{i h}\left(h=1,2, \ldots, m_{i}\right)$ represents the running time of component $i$ in each PM cycle. The minimal repair downtime of component $i$ during the $\mathrm{BW}$ period $[0, W]$ is

$$
T_{f d i}=T_{f i}\left[\delta_{i} \sum_{h=1}^{N_{i}} \int_{0}^{T_{i h}} \lambda_{i h}(t)+\sum_{h=1}^{\kappa_{i}} \int_{0}^{T_{i h}} \lambda_{i h}(t)\right] .
$$

Therefore, the minimal repair cost of the system during the $\mathrm{BW}$ period $[0, W]$ is

$$
\begin{aligned}
C_{f d} & =C_{D} S_{f d}=C_{D} \sum_{i=1}^{Q} T_{f d i} \\
& =C_{D} \sum_{i=1}^{Q}\left\{T_{f i}\left[\delta \sum_{h=1}^{N_{i}} \int_{0}^{T_{i h}} \lambda_{i h}(t)+\sum_{h=1}^{\kappa} \int_{0}^{T_{i h}} \lambda_{i h}(t)\right]\right\} .
\end{aligned}
$$

To sum up, the total maintenance cost of the series multi-component system during the BW period is the sum of the direct maintenance cost of each component and the total shutdown loss of the system:

$$
\begin{aligned}
E C(R)= & C_{z}+C_{p d}+C_{f d}=\sum_{i=1}^{Q} \sum_{n=1}^{N} C_{z i n}+C_{D} \sum_{n=1}^{N} S_{p d n} \\
& +C_{D} \sum_{i=1}^{Q}\left\{T_{f i}\left[\delta \sum_{h=1}^{N_{i}} \int_{0}^{T_{i h}} \lambda_{i h}(t)+\sum_{h=1}^{\kappa} \int_{0}^{T_{i h}} \lambda_{i h}(t)\right]\right\},
\end{aligned}
$$

where $R=\left(R_{1}, \ldots, R_{i}, \ldots, R_{Q}\right)$. Moreover, the OM optimization model with the goal of minimizing the total maintenance cost for the multi-component system during the BW period $[0, W]$ can be deduced, as shown as follows:

$$
\left\{\begin{array}{l}
\min \quad E C(R)=\sum_{i=1}^{Q} \sum_{n=1}^{N} C_{z i n}+C_{D} \sum_{n=1}^{N} S_{p d n}+C_{D} \sum_{i=1}^{Q}\left\{T_{f i}\left[\delta \sum_{h=1}^{N_{i}} \int_{0}^{T_{i h}} \lambda_{i h}(t)+\sum_{h=1}^{\kappa} \int_{0}^{T_{i h}} \lambda_{i h}(t)\right]\right\}, \\
\text { s.t. } \quad-\ln \left(R_{i \min }+R_{i}\right) \leq \int_{0}^{T_{i k}} \lambda_{i k}(t) \mathrm{d} t \leq-\ln R_{i \min }, \\
0 \leq R_{i} \leq \min _{1 \leq i \leq Q}\left(1-R_{i \min }\right) .
\end{array}\right.
$$


Hence, the optimal OM reliability threshold $R^{*}=\left(R_{1}^{*}, \ldots, R_{i}^{*}, \ldots, R_{Q}^{*}\right)$ can be obtained by minimizing the optimization model.

3.3. Solution Procedure of the OM Model for the Multi-component System. For the objective function $\operatorname{EC}\left(R_{1}, \ldots\right.$, $R_{i}, \ldots, R_{Q}$ ) of the OM model for the multi-component system, it can be calculated according to the OM reliability threshold $R_{i}$ of each component in the system. When a set of decision variables that meet the constraint conditions is given, the corresponding EC can be calculated. Specific steps are as follows: the algorithm flow is shown in Figure 6.

Step 1. Set the values of the relevant parameters, and obtain the optimal number $N_{i}^{*}$ of PM and the optimal PM interval $T_{i k}^{*}$ for component $i$ in the system according to the optimization of PM interval for a single component based on reliability.

Step 2. Let $t_{n}=\min \left(t_{1 n}, \ldots, t_{i n}, \ldots, t_{\mathrm{Qn}}\right)$ be the moment of the nth PM of the system, when $n=1$; there is $t_{11}=T_{11}, \ldots, t_{i 1}=T_{i 1}, \ldots, t_{\mathrm{Q} 1}=T_{\mathrm{Q} 1}$.

Step 3. Determine the reliability threshold $R_{i}$ of each component and the reliability $R_{i}\left(t_{n}\right)$ of component $i$ at $t_{n}$, and compare the values of $\left[R_{i}\left(t_{n}\right)-R_{i \text { min }}\right]$ and $R_{i}$. When $R_{i}\left(t_{n}\right)-R_{i \min }>R_{i}$, thus component $i$ does not need any maintenance actions at $t_{n}$; if $R_{i}\left(t_{n}\right)-R_{i \min }>R_{i}$, then at $t_{n}$, the opportunistic PM will be implemented on component $i$, and the number of PMs $n_{i}$ of component $i$ increases by 1 ; while $0<R_{i}\left(t_{n}\right)-R_{i \min } \leq R_{i}$ and $n_{i}=N_{i}+1$ and then $n_{i}=0$, it is necessary to carry out the opportunistic preventive replacement on component $i$.

Therefore, the time required for the maintenance action of component $i$ at $t_{n}$ is as follows:

$$
\begin{cases}0, & M_{i t_{n}}=B, \\ T_{p i}, & M_{i t_{n}}=Y, O, \\ T_{r i}, & M_{i t_{n}}=G, R .\end{cases}
$$

Then, the downtime of the system in the nth PM should be the longest maintenance time of all the components in this maintenance action, which is $S_{p d n}=\max _{1 \leq i \leq Q}\left(T_{p i}, T_{r i}\right)$.

Step 4. According to equation (11), the direct maintenance cost $C_{z i n}$ of component $i$ in the complete maintenance cycle from $t_{n}$ to $t_{n+1}$ is calculated; based on Equation (16), the shutdown loss caused by the nth PM of the system is calculated; finally, the minimal repair shutdown loss of the system can be obtained according to equation (18).

Step 5. After the nth PM of the system, determine the next PM moment of the system. According to the method of Step 2 , the moment $t_{n+1}$ of the $(n+1)$ th PM for the system is calculated. Repeat Step 2 to Step 4 until $t_{n}>W$. Substituting the data into equation (19), the total maintenance cost of the system during the BW period under the given OM reliability threshold will be obtained.

\section{Numerical Experiments}

4.1. Problem Description. Port machinery equipment is the material basis for the production and operation of port enterprises. This study takes the drive device of the BH45-1 belt conveyor in a certain port as the research object. The drive device is the power source for the operation of the belt conveyor. Its failure will cause the entire belt conveyor to stop and significant downtime loss. The OM strategy is implemented during the BW period. When a component in the drive device reaches its PM reliability threshold, the system will shut down and the imperfect PM or preventive replacement will be implemented; in the meanwhile, the OM conditions of other components in the drive device are judged, and the opportunistic imperfect PM or opportunistic preventive replacement will be performed on the components whose reliability reaches the OM reliability threshold. The belt conveyor drive device is mainly composed of five key components, such as electric motor, hydraulic coupler, reducer, low-speed coupling, and transmission drum. Five components form the series multi-component system, and its reliability block diagram is shown in Figure 7.

Assuming that the $\mathrm{BW}$ period of the drive device is 730 days, the shutdown loss of each component in the drive device is equal to the shutdown loss of the entire belt conveyor, that is, $50000 \mathrm{CNY} /$ day. In practice, the values of $\varphi_{i k}$ and $\delta_{i k}$ are usually random and uncertain. According to the experience of maintenance management personnel, this study assumes that $\delta_{i k}=0.09$ and $\varphi_{i k}=1.09$. According to the maintenance data of the belt conveyor drive device recorded by the port maintenance management department from October 2008 to March 2014 , we can get other parameters of the proposed model as given in Table 1 [46].

\subsection{Model Solution}

4.2.1. Solution of the Optimal PM Strategy for a Single Component Based on Reliability. According to the optimization model of PM interval for a single component based on reliability, the optimal PM interval $T_{i k}^{*}$ and the optimal number $N_{i}^{*}$ of PM of component $i$ within a life cycle can be obtained. The optimal PM strategy for each component of the belt conveyor drive device is shown in Table 2 .

As can be seen from Table 2, if OM strategy is not considered, only performing reliability-based PM or replacement on each component separately, the total maintenance cost of the drive device during the BW period can be obtained as follows: $3,648,175 \mathrm{CNY}$. In the meantime, the drive device will be out of service up to 77 times due to PM or replacement of each component. In the total maintenance cost, the direct maintenance cost is $1,081,138 \mathrm{CNY}$ and the shutdown loss cost is 2,567,037 CNY, accounting for $29.64 \%$ and $70.36 \%$ of the total maintenance cost, respectively. Hence, during BW period, the effective operation time of the driving device is 678.66 days; however, the total shutdown time is 51.34 days. Moreover, the downtime due to PM or 


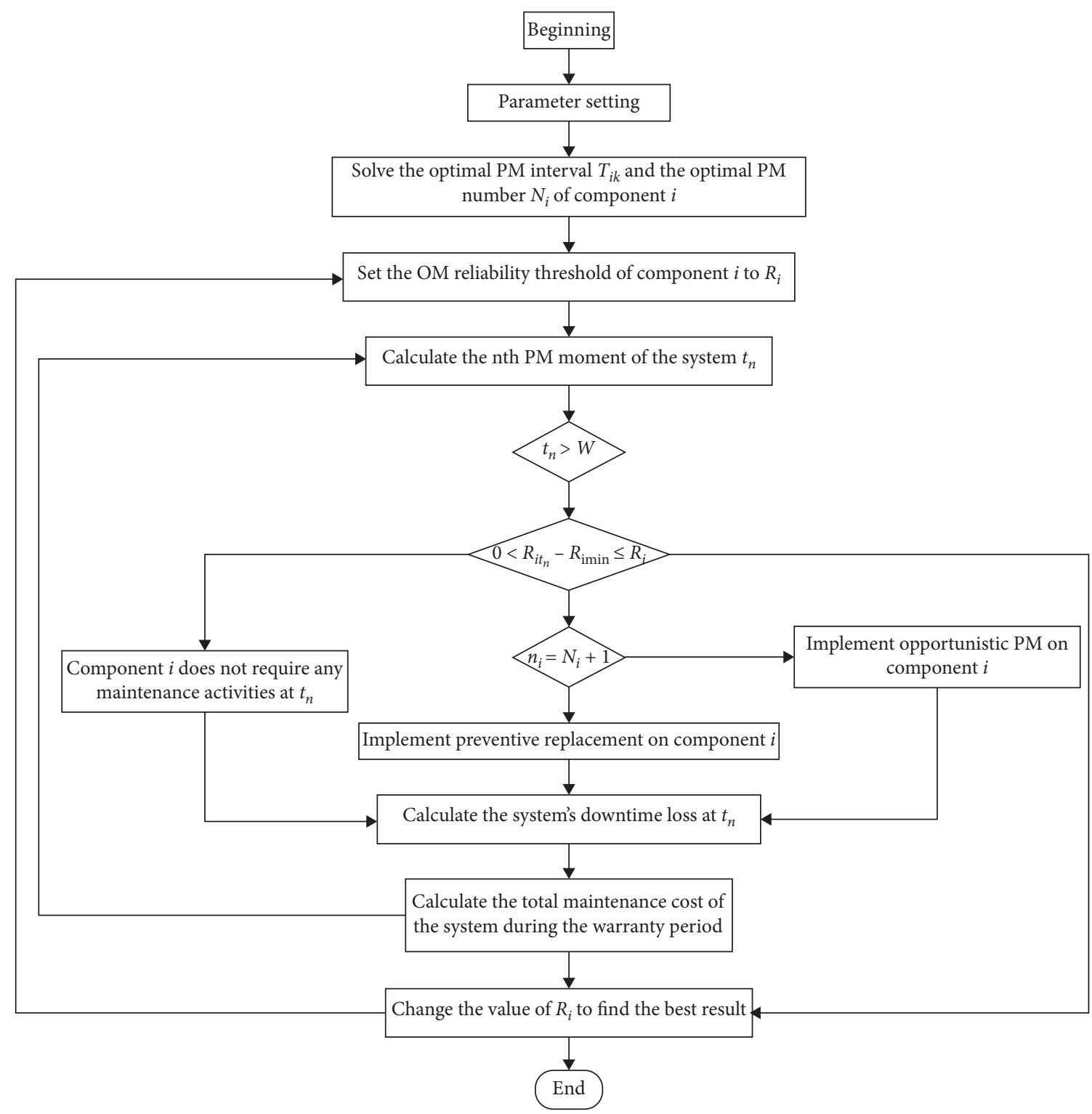

FIGURE 6: Algorithm flowchart of objective function.

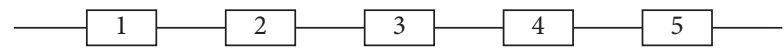
1. Motor
4. Low speed coupling
2. Hydrauli coupler
5. Transmission drum
3. Reducer

Figure 7: Reliability block diagram of the driving device.

TABle 1: The values of parameters in the presented numerical experiment.

\begin{tabular}{lccccccccc}
\hline Component & $\alpha_{i}$ & $\beta_{i}$ & $C_{p i}$ & $C_{f i}$ & $C_{r i}$ & $T_{p i}$ & $T_{f i}$ & $T_{r i}$ & $R_{i \text { min }}$ \\
\hline 1 & & & 87.13 & 1740 & 480 & 250000 & 0.38 & 0.13 & 0.92 \\
2 & 4.42 & 76.52 & 1080 & 300 & 116500 & 0.29 & 0.08 & 0.42 \\
3 & 3.13 & 60.19 & 2160 & 620 & 178500 & 0.42 & 0.17 & 1.10 & 0.50 \\
4 & 3.08 & 138.00 & 820 & 260 & 16100 & 0.20 & 0.10 & 0.55 \\
5 & 3.72 & 55.96 & 2800 & 500 & 62600 & 0.46 & 0.15 & 1.00 \\
\hline
\end{tabular}


TABLe 2: The optimal PM schedule for each component of the drive device.

\begin{tabular}{lcccccccccccccc}
\hline \multirow{2}{*}{ Component } & \multicolumn{1}{c}{$T_{i 1}^{*}$} & $T_{i 2}^{*}$ & $T_{i 3}^{*}$ & $T_{i 4}^{*}$ & $T_{i 5}^{*}$ & $T_{i 6}^{*}$ & $T_{i 7}^{*}$ & $T_{i 8}^{*}$ & $T_{i 9}^{*}$ & $T_{i 10}^{*}$ & $T_{i 11}^{*}$ & $T_{i 12}^{*}$ & $E C_{i}^{*}$ & $N_{i}^{*}$ \\
& 74.8 & 66.7 & 59.3 & 52.6 & 46.5 & 41.2 & 36.4 & 32.1 & 28.4 & 25.1 & 22.2 & 19.7 & 1109.8 & 11 \\
1 & 68.1 & 60.1 & 53.0 & 46.7 & 41.1 & 36.2 & 32.0 & 28.3 & 25.1 & 22.3 & - & - & 738.7 \\
2 & 48.4 & 42.7 & 37.6 & 33.1 & 29.2 & 25.7 & 22.7 & 20.1 & 17.8 & 15.8 & - & - & 1634.1 & 9 \\
3 & 125.1 & 110.9 & 98.2 & 86.8 & 76.6 & 67.6 & - & - & - & - & - & - & 210.9 & 5 \\
4 & 46.0 & 40.4 & 35.5 & 31.2 & 27.5 & 24.3 & 21.5 & - & - & - & - & - & 1304.0 & 6 \\
5 & & & & & & & & & &
\end{tabular}

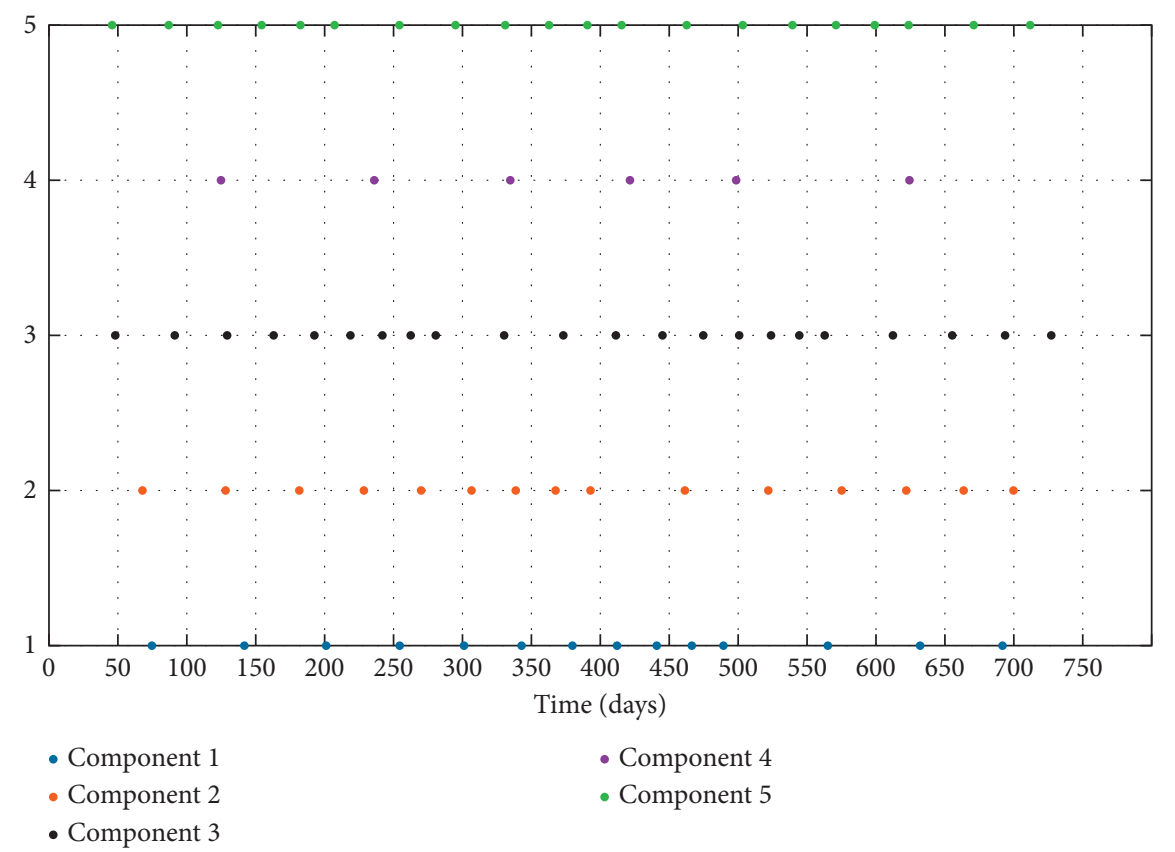

Figure 8: The optimal PM plan for each component of the drive device.

replacement and minimal repair is 33.31 days and 18.03 days, respectively. Therefore, the availability of the drive device during BW period can be derived as 0.9297. Based on the data in Table 2 and the above analysis, we can obtain the optimal PM plan for each component of the belt conveyor drive device during the whole BW period, as shown in Figure 8.

It should be noted that, for each component, each point represents the PM or replacement moment in Figure 8. More specifically, the point where the PM interval becomes larger is the preventive replacement moment of the component. Obviously, PM actions are irregular and the point where the maintenance interval suddenly becomes larger is the preventive replacement moment of the component, which is consistent with the fact that the overall trend of the failure rate of the component after imperfect repair is gradually increasing and the PM reliability threshold is a certain amount.

4.2.2. SA for the Solution of OM Model of the Multi-component System. SA was firstly put forward by Metropolis [47], which simulates the physical annealing process of hot atoms using statistical thermodynamics, where atoms become less and less active until frozen as the temperature decreases. SA algorithm is a random optimization algorithm. Therefore, at every temperature, a new state of atoms is accepted when the system performance becomes better; furthermore, a worse state will also be accepted under a certain probability [48]. In this study, the SA algorithm is developed to optimize the maintenance cost of the multi-component system during the BW period in order to figure out the optimal OM reliability threshold $R^{*}=$ $\left(R_{1}^{*}, \ldots, R_{i}^{*}, \ldots, R_{Q}^{*}\right)$, hence obtaining the minimal maintenance cost. It shows that the question of local minimization can be avoided effectively using the SA algorithm, which also can reduce the computation time.

The basic framework of the SA algorithm is shown in Figure 9.

More specifically, the procedure of the proposed optimal OM method of the multi-component system is summarized in Algorithm 1.

In the meantime, the parameter initialization of the SA algorithm is set as in Table 3 .

According to the parameter values, in our observation, after a hundred iterations, SA converges to a stable state quickly. Moreover, the current temperature is close to zero. 


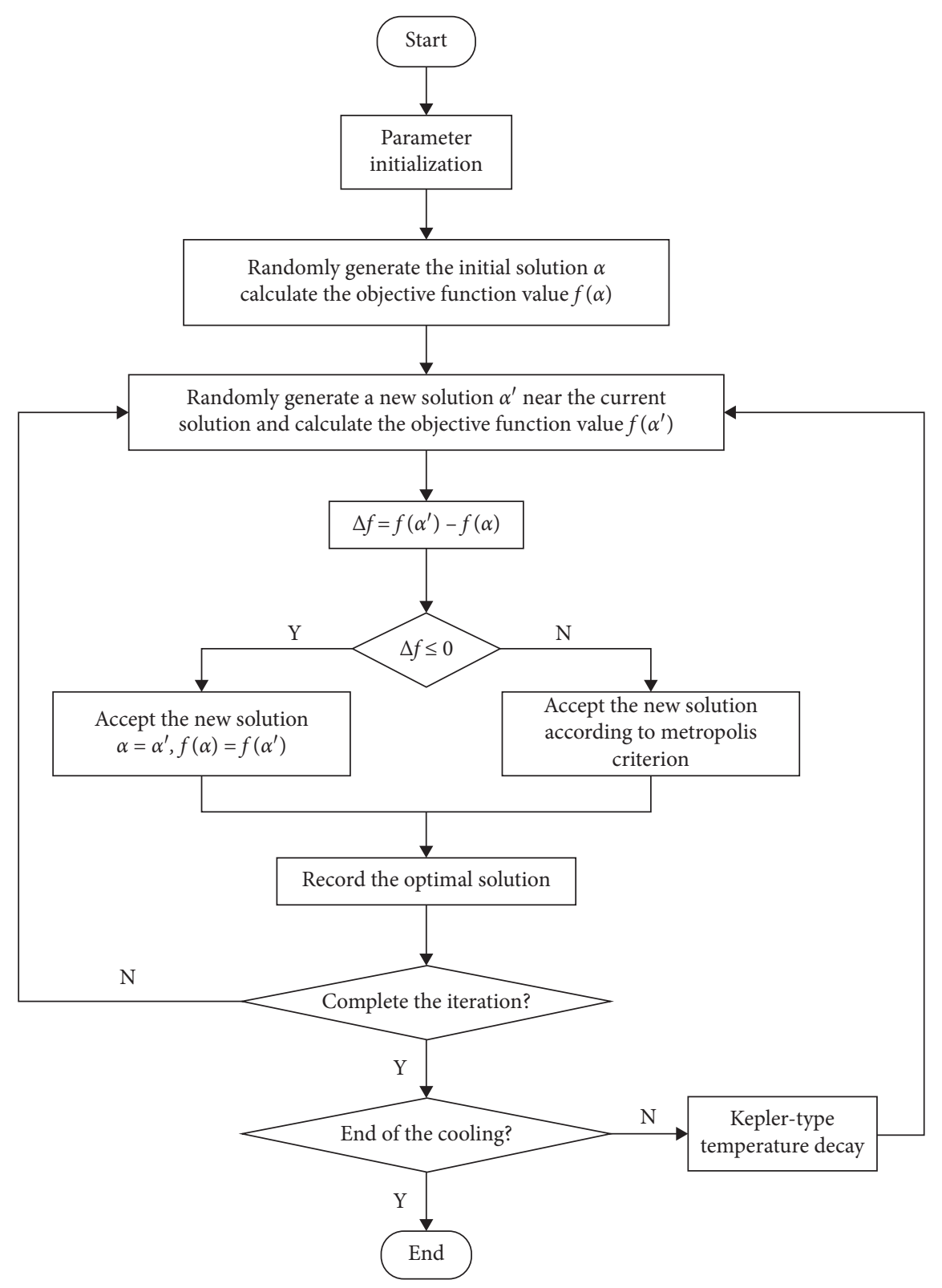

Figure 9: Flowchart of the proposed SA algorithm.

Then, we can draw the conclusion that the SA has found the global optimal value. The convergence of SA algorithm is shown in Figure 10.

From Figure 10, it can be seen that the optimal value of the objective function is $3,242,080 \mathrm{CNY}$ with the optimal values of five variables; that is, the OM reliability thresholds of each component are $(0.383,0.381,0.246,0.383,0.286)$; namely, $R^{*}=\left(R_{1}^{*}, R_{2}^{*}, R_{3}^{*}, R_{4}^{*}, R_{5}^{*}\right)=(0.383,0.381,0.246$, $0.383,0.286)$.

\subsection{Results Analysis}

4.3.1. The Optimal OM Schedule for the Belt Conveyor Drive Device. Based on the above analysis and data, the optimal total maintenance cost of the drive device system is 3,242,080 CNY, in which, the direct maintenance cost is $1,578,614 \mathrm{CNY}$ and the shutdown loss cost is $1,663,466 \mathrm{CNY}$, accounting for $48.69 \%$ and $51.31 \%$ of the total maintenance cost, respectively. Meanwhile, the number of shutdowns of the drive device is up to 22 times due to PM or replacement of each component. Hence, during the BW period, the effective operation time of the driving device is 696.73 days; however, the total shutdown time is 33.27 days. Moreover, the downtime due to PM or replacement and minimal repair is 13.49 days and 19.78 days, respectively. Therefore, the availability of the drive device during the BW period can be derived as 0.954 . Then, the optimal OM schedule for the drive device is presented in Table 4 .

Based on the data in Table 4 and the above analysis, we can propose the optimal OM schedule for the belt conveyor drive device during the whole $\mathrm{BW}$ period, including the specific maintenance strategy of each component during each shutdown of the system, as shown in Figure 11. 
Input: Initial solution $R_{\text {initial }}$, max temperature $T_{\max }$, cooling schedule $g(\cdot)$, interloop count $L$.

Output: Best solution $R_{\text {best }}$ found.

(1) $s=R_{\text {initial }}$

(2) $T=T_{\max }$;

(3) while stop conditions unsatisfied do

(4) for $l=1: L$ do

(5) Generate a random neighbor $s / \in N(\Delta R)$;

(6) $\Delta f=f(s \prime)-f(s)$;

(7) if $\Delta f \leq 0$ then

(8) $s=s$ I

(9) else

(10) $\quad$ if $\operatorname{random}(0,1)<\exp (-\Delta f / T)$ then $s=s /$; / random $(0,1)$ generates a random real number in $[0,1]$.

(11) end if

(12) end for

(13) $T=g(T)$;

(14) end while

(15) Output $R_{\text {best }}$.

(16) Calculate the optimized maintenance cost of the drive device considering the OM strategy.

Algorithm 1: Optimization of the maintenance cost of the drive device considering the OM strategy.

TABLE 3: SA parameters.

\begin{tabular}{lc}
\hline Parameter & Value \\
\hline$T_{\text {max }}:$ initial temperature & 100 \\
Number of iterations to stop & 100 \\
$L:$ number of iterations at each temperature & 1 \\
Cooling rate & 0.9 \\
Value range of the variable $R_{i}$ & {$[0,0.5]$} \\
$R_{\text {initial }}:$ initial value of the variables & 0.1 \\
\hline
\end{tabular}

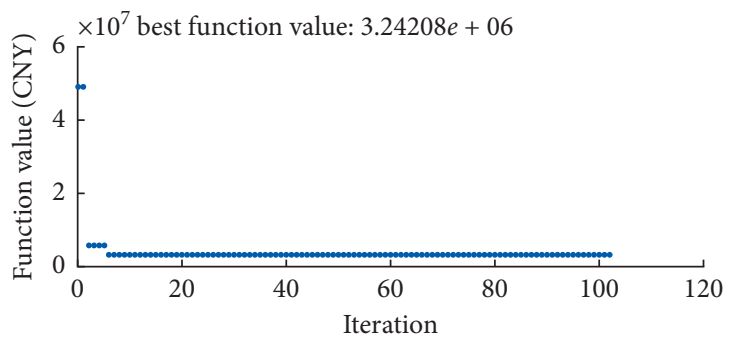

(a)

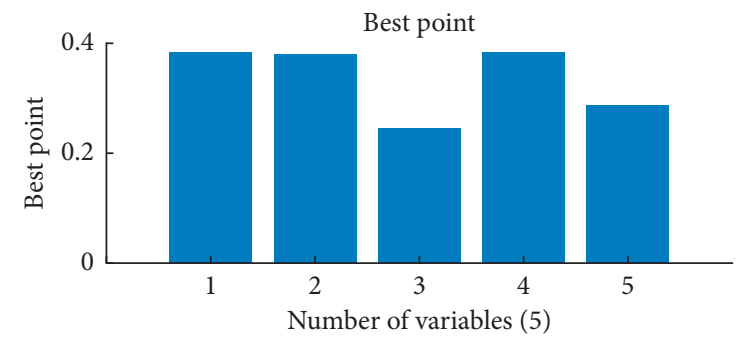

(b)

Figure 10: The convergence of SA algorithm for the maintenance cost optimization.

To reflect the optimization degree of the OM strategy for the maintenance cost of the multi-component system with economic dependence, the results of various aspects of the drive device before and after considering the OM strategy are shown in Table 5.

By analyzing Table 5, we can see that the implementation of the OM strategy for the drive device can give full consideration to the interests of manufacturers and users during the BW period. Since for one thing, the total maintenance cost that the manufacturer has to bear is reduced; for another, the availability of the drive device is improved, and the downtime is reduced, thus users can get more benefits. In addition, it should be noted that the direct maintenance cost has increased to a certain extent, which is consistent with the actual maintenance process of the OM strategy. This is because some components in the drive device have been opportunistically repaired or replaced in advance.

4.3.2. Reliability Analysis for the Components of Belt Conveyor Drive Device. According to the PM strategy for single components based on reliability, when the reliability of component reaches the PM reliability threshold, it is necessary to carry out PM or replacement on it. After considering the OM strategy, the opportunistic 
TABLE 4: The optimal OM schedule for the belt conveyor drive device.

\begin{tabular}{|c|c|c|c|c|c|}
\hline \multirow{2}{*}{$T$ (days) } & \multicolumn{5}{|c|}{ Maintenance strategy } \\
\hline & 1 & 2 & 3 & 4 & 5 \\
\hline 46.0 & $\mathrm{O}$ & $\mathrm{O}$ & $\mathrm{O}$ & $\mathrm{B}$ & $\mathrm{Y}$ \\
\hline 86.9 & $\mathrm{O}$ & $\mathrm{O}$ & $\mathrm{O}$ & $\mathrm{O}$ & $\mathrm{Y}$ \\
\hline 122.9 & $\mathrm{O}$ & $\mathrm{O}$ & $\mathrm{O}$ & $\mathrm{B}$ & $\mathrm{Y}$ \\
\hline 154.5 & $\mathrm{O}$ & $\mathrm{O}$ & $\mathrm{O}$ & $\mathrm{B}$ & $\mathrm{Y}$ \\
\hline 182.5 & $\mathrm{O}$ & $\mathrm{O}$ & $\mathrm{O}$ & $\mathrm{O}$ & $\mathrm{Y}$ \\
\hline 207.2 & $\mathrm{O}$ & $\mathrm{O}$ & $\mathrm{O}$ & $\mathrm{B}$ & G \\
\hline 242.0 & $\mathrm{O}$ & $\mathrm{O}$ & $\mathrm{Y}$ & $\mathrm{O}$ & $\mathrm{O}$ \\
\hline 262.5 & $\mathrm{O}$ & $\mathrm{O}$ & $\mathrm{Y}$ & $\mathrm{B}$ & $\mathrm{O}$ \\
\hline 280.8 & $\mathrm{O}$ & $\mathrm{R}$ & G & $\mathrm{B}$ & $\mathrm{O}$ \\
\hline 330.2 & $\mathrm{O}$ & $\mathrm{O}$ & $\mathrm{Y}$ & $\mathrm{O}$ & $\mathrm{O}$ \\
\hline 373.4 & $\mathrm{R}$ & $\mathrm{O}$ & $\mathrm{Y}$ & $\mathrm{R}$ & $\mathrm{O}$ \\
\hline 411.4 & $\mathrm{O}$ & $\mathrm{O}$ & $\mathrm{Y}$ & $\mathrm{B}$ & $\mathrm{R}$ \\
\hline 445.0 & $\mathrm{O}$ & $\mathrm{O}$ & $\mathrm{Y}$ & $\mathrm{O}$ & $\mathrm{O}$ \\
\hline 474.6 & $\mathrm{O}$ & $\mathrm{O}$ & $\mathrm{Y}$ & B & $\mathrm{O}$ \\
\hline 500.7 & $\mathrm{O}$ & $\mathrm{O}$ & $\mathrm{Y}$ & $\mathrm{O}$ & $\mathrm{O}$ \\
\hline 523.9 & $\mathrm{O}$ & $\mathrm{O}$ & $\mathrm{Y}$ & B & $\mathrm{O}$ \\
\hline 544.4 & $\mathrm{O}$ & $\mathrm{O}$ & $\mathrm{Y}$ & $\mathrm{O}$ & $\mathrm{O}$ \\
\hline 562.6 & $\mathrm{O}$ & $\mathrm{R}$ & $\mathrm{G}$ & B & $\mathrm{R}$ \\
\hline 612.1 & $\mathrm{O}$ & $\mathrm{O}$ & $\mathrm{Y}$ & $\mathrm{O}$ & $\mathrm{O}$ \\
\hline 655.2 & $\mathrm{O}$ & $\mathrm{O}$ & $\mathrm{Y}$ & $\mathrm{R}$ & $\mathrm{O}$ \\
\hline 693.3 & $\mathrm{O}$ & $\mathrm{O}$ & $\mathrm{Y}$ & $\mathrm{O}$ & $\mathrm{O}$ \\
\hline 726.8 & $\mathrm{R}$ & $\mathrm{O}$ & $\mathrm{Y}$ & $\mathrm{O}$ & $\mathrm{O}$ \\
\hline- & - & - & - & - & - \\
\hline- & - & - & - & - & - \\
\hline
\end{tabular}

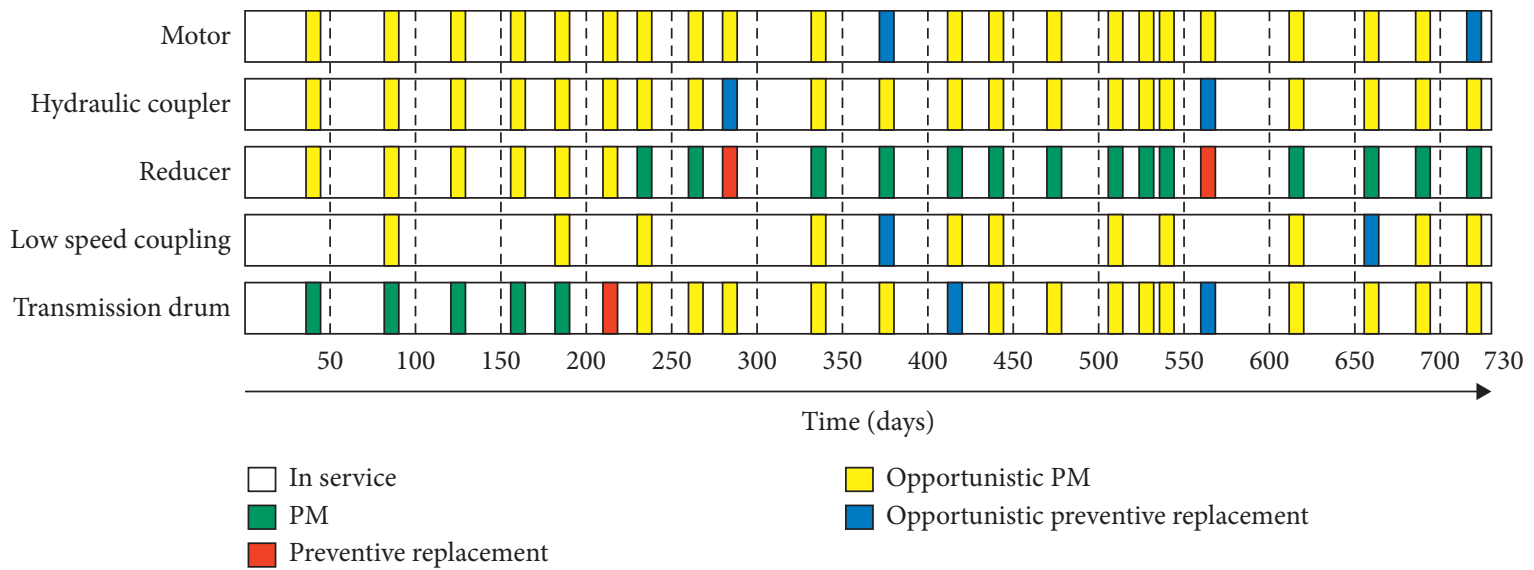

Figure 11: OM schedule of the belt conveyor drive device.

PM or replacement may be performed before the PM reliability threshold of the component is reached. In the OM model of the belt conveyor drive device, the optimal OM reliability threshold of each component is $R^{*}=(0.383,0.381,0.246,0.383,0.286)$, while the PM reliability threshold of each component is $R_{i \text { min }}=(0.60$, $0.50,0.60,0.50,0.55)$. Therefore, when the reliability of the component $R_{i}(t) \leq(0.983,0.881,0.846,0.883,0.836)$, there is an opportunity to perform PM or replacement on the component. Moreover, the reliability of the components in the drive device varies with the operating time as shown in Figure 12.

As can be seen from Figure 12, when we perform PM actions, the reliability of the components does not necessarily reach the PM reliability threshold. In the operation process during the BW period, after each replacement of the component in the drive device, the PM intervals of the components are getting shorter and shorter, which is consistent with the optimal OM schedule for the belt conveyor drive device. 
TABLE 5: The comparison before and after considering the OM strategy on some important indicators.

\begin{tabular}{lccc}
\hline Indicator & Not considering the OM & Considering the OM & Optimization degree (\%) \\
\hline Total maintenance cost & $3,648,175 \mathrm{CNY}$ & $3,242,080 \mathrm{CNY}$ & 11.13 \\
Availability & 0.9297 & 0.9544 & 2.66 \\
Direct maintenance cost & $1,081,138 \mathrm{CNY}$ & $1,578,614 \mathrm{CNY}$ & -46.01 \\
Shutdown loss cost & $2,567,037 \mathrm{CNY}$ & $1,663,466 \mathrm{CNY}$ & 35.20 \\
Number of shutdowns & 77 & 22 & 76.71 \\
\hline
\end{tabular}

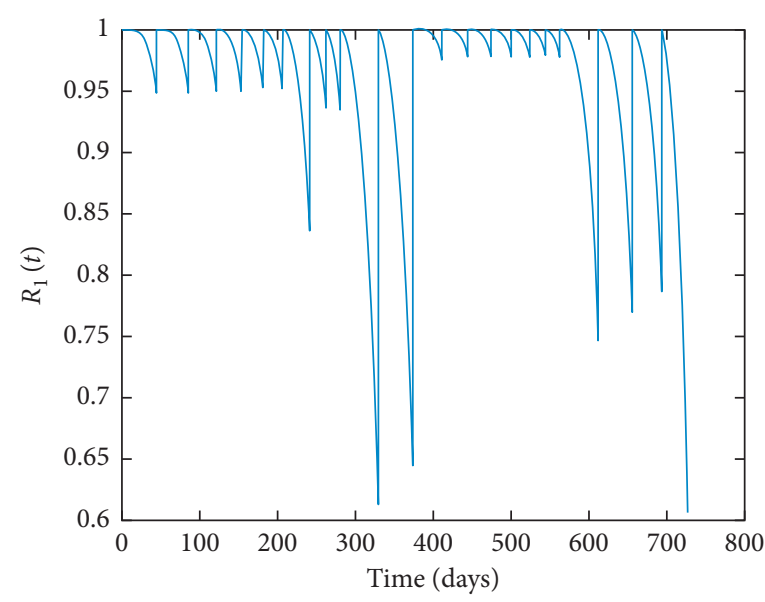

(a)

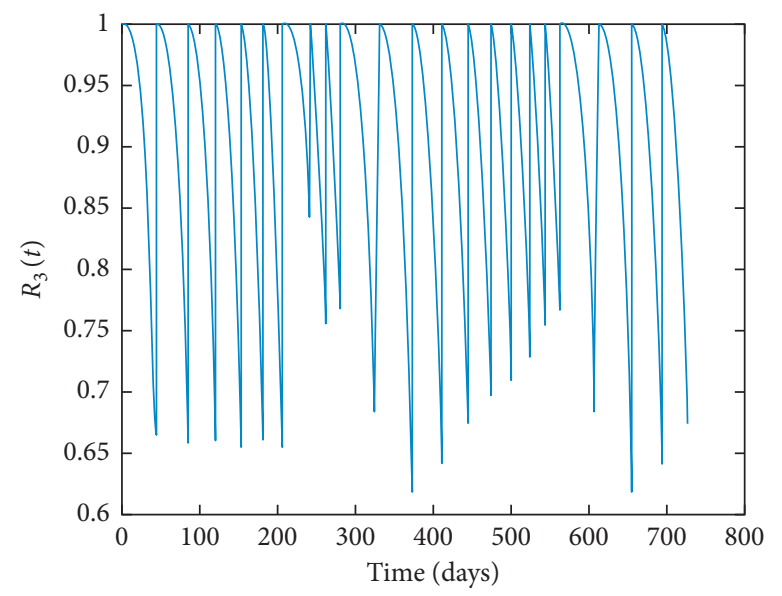

(c)

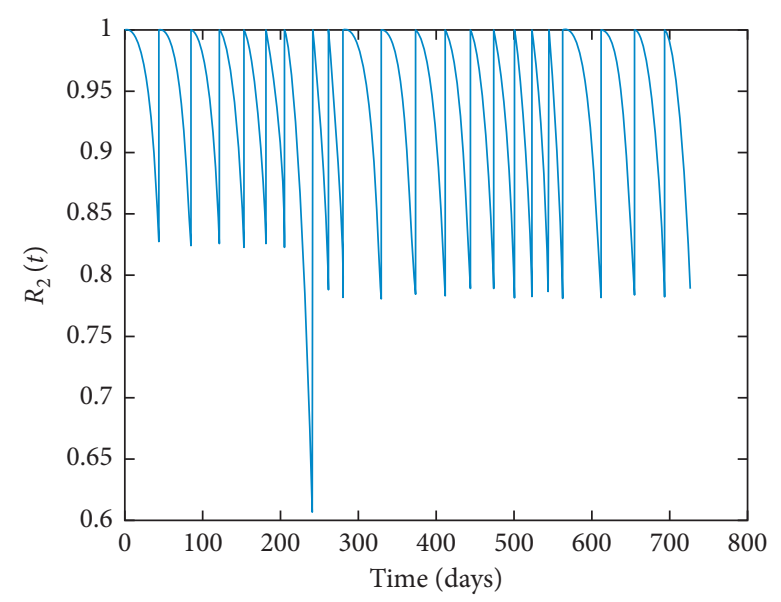

(b)

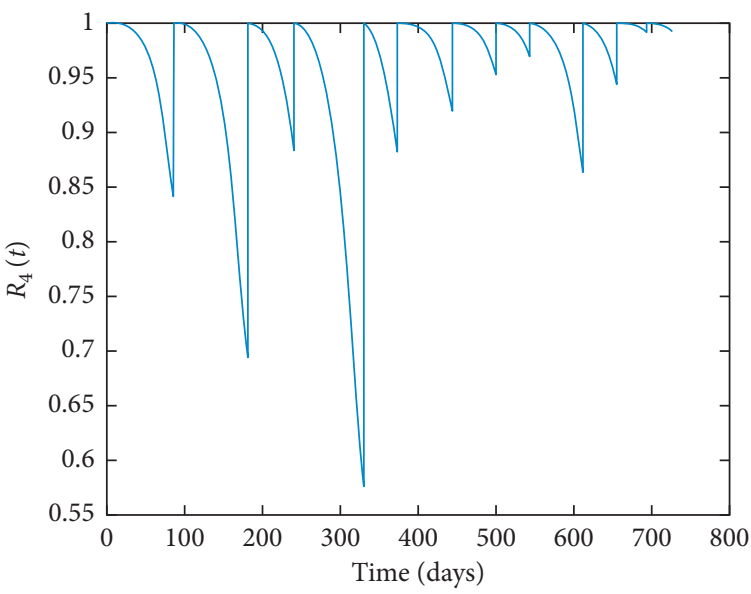

(d)

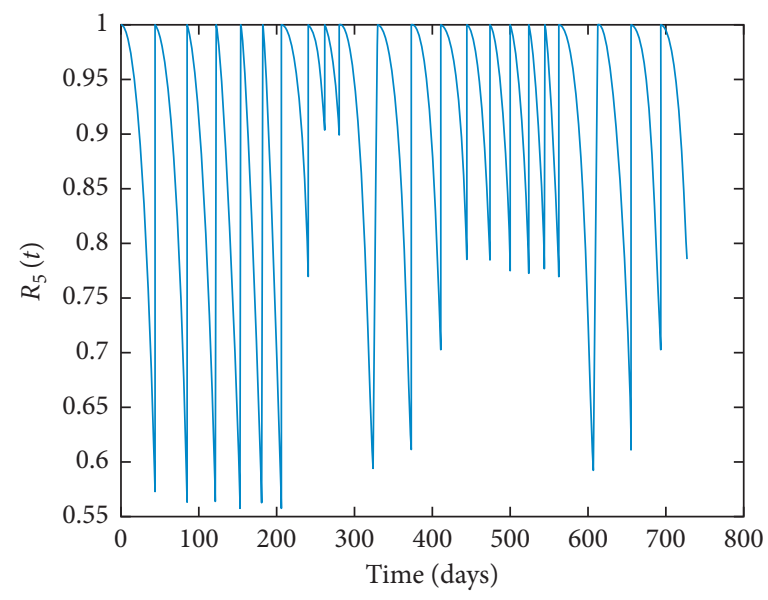

(e)

FIGURE 12: The chart of the component reliability varying with the operating time. 


\section{Conclusions}

In this paper, we investigate the reliability-based $\mathrm{OM}$ strategy for the belt conveyor drive device in a port, taking into account the impact of imperfect repair on the failure rate of the drive device. For this purpose, a hybrid failure rate model that combines the age reduction factor and failure rate increase factor is employed to construct the failure rate function of the components. The reliability-based PM threshold and OM threshold are then proposed to develop the PM model for single components and the OM model of the multi-component system. This study also proposed an irregular imperfect PM strategy in order to better fit the actual situation where the overall trend of component failure rate is rising. The presented model is finally applied for maintenance cost optimization of a belt conveyor drive device in a port. The optimized maintenance schedule and the information on the maintenance cost are determined based on the proposed method. The numerical results demonstrate that the OM strategy can significantly reduce the maintenance cost compared with separate PM and improve the availability of the drive device. It can be concluded that the developed model provides an economically efficient method of the belt conveyor drive device maintenance planning.

\section{Data Availability}

All data generated or analyzed during this study are included within this article.

\section{Conflicts of Interest}

The authors declare that they have no conflicts of interest.

\section{Acknowledgments}

The research work was financially supported by the National Natural Science Foundation of China (no. 71871219).

\section{References}

[1] X. Wang and W. Xie, "Two-dimensional warranty: a literature review," Proceedings of the Institution of Mechanical Engineers, Part O: Journal of Risk and Reliability, vol. 232, no. 3, pp. 284-307, 2018.

[2] A. Dai, G. Wei, Z. Zhang, and S. He, "Design of a flexible preventive maintenance strategy for two-dimensional warranted products," Proceedings of the Institution of Mechanical Engineers, Part O: Journal of Risk and Reliability, vol. 234, no. 1, pp. 74-87, 2020.

[3] D. N. P. Murthy and I. Djamaludin, "New product warranty: a literature review," International Journal of Production Economics, vol. 79, no. 3, pp. 231-260, 2002.

[4] N. Jack, B. P. Iskandar, and D. N. P. Murthy, "A repair-replace strategy based on usage rate for items sold with a twodimensional warranty," Reliability Engineering \& System Safety, vol. 94, no. 2, pp. 611-617, 2009.

[5] W. R. Blischke and D. N. P. Murthy, Warranty Cost Analysis, Marcel Dekker, New York, NY, USA, 1994.
[6] C.-W. Yeh and C.-C. Fang, "Optimal pro-rata warranty decision with consideration of the marketing strategy under insufficient historical reliability data," The International Journal of Advanced Manufacturing Technology, vol. 71, no. 9-12, pp. 1757-1772, 2014.

[7] S. He, Z. Zhang, G. Zhang, and Z. He, "Two-dimensional base warranty design based on a new demand function considering heterogeneous usage rate," International Journal of Production Research, vol. 55, no. 23, pp. 7058-7072, 2017.

[8] P. Tong, Z. Liu, F. Men, and L. Cao, "Designing and pricing of two-dimensional extended warranty contracts based on usage rate," International Journal of Production Research, vol. 52, no. 21, pp. 6362-6380, 2014.

[9] Z.-S. Ye and D. N. P. Murthy, "Warranty menu design for a two-dimensional warranty," Reliability Engineering \& System Safety, vol. 155, pp. 21-29, 2016.

[10] Y.-S. Huang, C.-D. Huang, and J.-W. Ho, "A customized twodimensional extended warranty with preventive maintenance," European Journal of Operational Research, vol. 257, no. 3, pp. 971-978, 2017.

[11] S. M. Majidi, A. Yazdekhasti, and A. Yousefi, "Bi-objective optimization of basic and extended warranty policies regarding preventive maintenance and burn-in policies: Weibull bathtub-shaped failure rate," Life Cycle Reliability and Safety Engineering, vol. 9, no. 4, pp. 359-377, 2020.

[12] R. Zheng and C. Su, "A flexible two-dimensional basic warranty policy with two continuous warranty regions," Quality and Reliability Engineering International, vol. 36, no. 6, pp. 2003-2018, 2020.

[13] Z. He, D. Wang, S. He, Y. Zhang, and A. Dai, "Twodimensional extended warranty strategy including maintenance level and purchase time: a win-win perspective," Computers \& Industrial Engineering, vol. 141, 2020.

[14] J. C. Hartman and K. Laksana, "Designing and pricing menus of extended warranty contracts," Naval Research Logistics (NRL), vol. 56, no. 3, pp. 199-214, 2009.

[15] D. H. Dinh, P. Do, and B. Iung, "Degradation modeling and reliability assessment for a multi-component system with structural dependence," Computers \& Industrial Engineering, vol. 144, 2020.

[16] Y. Zhou, L. Ma, J. Mathew, Y. Sun, and R. Wolff, "Maintenance strategy optimization using a continuous-state partially observable semi-Markov decision process," Microelectronics Reliability, vol. 51, no. 2, pp. 300-309, 2011.

[17] S. Bouguerra, A. Chelbi, and N. Rezg, "A decision model for adopting an extended warranty under different maintenance policies," International Journal of Production Economics, vol. 135, no. 2, pp. 840-849, 2012.

[18] R. P. Nicolai and R. Dekker, "Optimal maintenance of multicomponent systems: a review," Springer Series in Reliability Engineering, vol. 8, no. 1991, pp. 263-286, 2008.

[19] J. Hu, J. Shen, and L. Shen, "Opportunistic maintenance for two-component series systems subject to dependent degradation and shock," Reliability Engineering \& System Safety, vol. 201, 2020.

[20] L. C. Thomas, "A survey of maintenance and replacement models for maintainability and reliability of multi-item systems," Reliability Engineering, vol. 16, no. 4, pp. 297-309, 1986.

[21] L. Yang, Y. Zhao, and X. Ma, "Group maintenance scheduling for two-component systems with failure interaction," Applied Mathematical Modelling, vol. 71, pp. 118-137, 2019.

[22] N. Chalabi, M. Dahane, B. Beldjilali, and A. Neki, "Optimisation of preventive maintenance grouping strategy for multi- 
component series systems: particle swarm based approach," Computers \& Industrial Engineering, vol. 102, pp. 440-451, 2016.

[23] C. D. Dao, M. J. Zuo, and M. Pandey, "Selective maintenance for multi-state series-parallel systems under economic dependence," Reliability Engineering \& System Safety, vol. 121, pp. 240-249, 2014.

[24] M. C. A. Olde Keizer, S. D. P. Flapper, and R. H. Teunter, "Condition-based maintenance policies for systems with multiple dependent components: a review," European Journal of Operational Research, vol. 261, no. 2, pp. 405-420, 2017.

[25] X. Zhou, K. Huang, L. Xi, and J. Lee, "Preventive maintenance modeling for multi-component systems with considering stochastic failures and disassembly sequence," Reliability Engineering \& System Safety, vol. 142, pp. 231-237, 2015.

[26] P. Do, R. Assaf, P. Scarf, and B. Iung, "Modelling and application of condition-based maintenance for a twocomponent system with stochastic and economic dependencies," Reliability Engineering \& System Safety, vol. 182, pp. 86-97, 2019.

[27] R. Barlow and L. Hunter, "Optimum preventive maintenance policies," Operations Research, vol. 8, no. 1, pp. 90-100, 1960.

[28] M. Park, K. M. Jung, and D. H. Park, "Optimization of periodic preventive maintenance policy following the expiration of two-dimensional warranty," Reliability Engineering \& System Safety, vol. 170, pp. 1-9, 2018.

[29] X. Zhang and J. Zeng, "Deterioration state space partitioning method for opportunistic maintenance modelling of identical multi-unit systems," International Journal of Production Research, vol. 53, no. 7, pp. 2100-2118, 2015.

[30] P. Do, H. C. Vu, A. Barros, and C. Bérenguer, "Maintenance grouping for multi-component systems with availability constraints and limited maintenance teams," Reliability Engineering \& System Safety, vol. 142, pp. 56-67, 2015.

[31] P. Do Van, A. Barros, C. Bérenguer, K. Bouvard, and F. Brissaud, "Dynamic grouping maintenance with time limited opportunities," Reliability Engineering \& System Safety, vol. 120, pp. 51-59, 2013.

[32] F. Santos, Â. P. Teixeira, and C. G. Soares, "Modelling and simulation of the operation and maintenance of offshore wind turbines," Proceedings of the Institution of Mechanical Engineers, Part O: Journal of Risk and Reliability, vol. 229, no. 5, pp. 385-393, 2015.

[33] Q. Yuan, Z. Jin, S. Jia, and Q. Liu, “An improved opportunity maintenance model of complex system," Advances in $\mathrm{Me}$ chanical Engineering, vol. 11, no. 4, pp. 1-19, 2019.

[34] B. Zhou, J. Yu, J. Shao, and D. Trentesaux, "Bottleneck-based opportunistic maintenance model for series production systems," Journal of Quality in Maintenance Engineering, vol. 21, no. 1, pp. 70-88, 2015.

[35] H. Ab-Samat and S. Kamaruddin, "Opportunistic maintenance $(\mathrm{OM})$ as a new advancement in maintenance approaches," Journal of Quality in Maintenance Engineering, vol. 20, no. 2, pp. 98-121, 2014.

[36] F. Ding and Z. Tian, "Opportunistic maintenance for wind farms considering multi-level imperfect maintenance thresholds," Renewable Energy, vol. 45, pp. 175-182, 2012.

[37] C. A. V. Cavalcante and R. S. Lopes, "Multi-criteria model to support the definition of opportunistic maintenance policy: a study in a cogeneration system," Energy, vol. 80, pp. 32-40, 2015.

[38] H. C. Vu, P. Do, M. Fouladirad, and A. Grall, "Dynamic opportunistic maintenance planning for multi-component redundant systems with various types of opportunities," Reliability Engineering \& System Safety, vol. 198, 2020.

[39] F. Ding and Z. Tian, "Opportunistic maintenance optimization for wind turbine systems considering imperfect maintenance actions," International Journal of Reliability, Quality and Safety Engineering, vol. 18, no. 05, pp. 463-481, 2011.

[40] N. Zhang, M. Fouladirad, and A. Barros, "Optimal imperfect maintenance cost analysis of a two-component system with failure interactions," Reliability Engineering \& System Safety, vol. 177, pp. 24-34, 2018.

[41] A. Ben Mabrouk, A. Chelbi, and M. Radhoui, "Optimal imperfect preventive maintenance policy for equipment leased during successive periods," International Journal of Production Research, vol. 54, no. 17, pp. 5095-5110, 2016.

[42] M. A. K. Malik, "Reliable preventive maintenance scheduling," A I I E Transactions, vol. 11, no. 3, pp. 221-228, 1979.

[43] J. Kang and C. Guedes Soares, "An opportunistic maintenance policy for offshore wind farms," Ocean Engineering, vol. 216, 2020.

[44] T. Nakagawa, "Sequential imperfect preventive maintenance policies," IEEE Transactions on Reliability, vol. 37, no. 3, pp. 295-298, 1988.

[45] D. Lin, M. J. Zuo, and R. C. M. Yam, "General sequential imperfect preventive maintenance models," International Journal of Reliability, Quality and Safety Engineering, vol. 07, no. 03, pp. 253-266, 2000.

[46] J. Chang, "Research on the opportunistic preventive maintenance strategy of multi-component equipment system," Master's Dissertation, Yanshan University, Qinhuangdao, China, 2014.

[47] N. Metropolis, A. W. Rosenbluth, M. N. Rosenbluth, A. H. Teller, and E. Teller, "Equation of state calculations by fast computing machines," The Journal of Chemical Physics, vol. 21, no. 6, pp. 1087-1092, 1953.

[48] X. Hao, J. Liu, Y. Zhang, and G. Sanga, "Mathematical model and simulated annealing algorithm for Chinese high school timetabling problems under the new curriculum innovation," Frontiers of Computer Science, vol. 15, no. 1, 2021. 